\title{
Possibilities of Pre-Hospital Intervention in the Pre- vention and Treatment of Covid-19 Recommendations of the Hungarian Integrative Medicine Association
}

\author{
Ivan Szalkai ${ }^{1 \star}$, Andrea Radnai ${ }^{2}$, Ferenc Karácsony ${ }^{1}$, Janos Körmendy-Rácz ${ }^{3}$, Andrea \\ Nyerges $^{4}$ and Gabriella Hegyi ${ }^{1}$
}

${ }^{1}$ Hungarian Integrative Medicine Society

${ }^{2}$ Hungarian Homeopathic Medical Association

${ }^{3}$ Hungarian Apiterapy Association

${ }^{4}$ Hungarian Scientific Ayurveda Association

\begin{abstract}
Over the Covid-19 pandemic, the whole world withdraws in the interest of the isolation and eradication of the disease. Governments over the world have ordered the narrowing of mobility, the usage of self-protective equipments, and invest tremendous efforts in finding the tools of treatment and vaccination. However, nobody mentions therapeutic options applicable in the prehospital phase regarding those prestigious methods with great traditions such as the integrative and complementary medicines. Therefore, according to observations of the elements of the disease process, we divided and categorized the practices which individuals can simply and easily exercise in their homes, acting upon verificationally effective advices that approve to enhance immunity along with the reduction of viral effects. We based our examinations on the methods and tools of Ayurveda, apitherapy, phytotherapy, homeopathy, and oxygen therapy. Our suggestions do not explain treatments of intensive care under hospitalization.
\end{abstract}

Corresponding author: Szalkai Iván, Hungarian Integrative Medicine Society. Email: szalkai1@outlook.hu

Received: May 01, 2020; Accepted: May 08, 2020; Published: May 11, 2020

Keywords: Covid-19, Prevention, Ayurveda, Apitherapy, Phitotherapy, Homeopathy, and Oxygen therapy

\section{Introduction}

The COVID-19 pandemic is currently nearing its peak, it is now descending in China, and in South Korea, but it is still converging upward in the US. The steps taken to curb the virus are broadly the same worldwide, reflecting the WHO resolution enactments. (Situation reports 2020)
In connection with the pandemic, several resolutions and government arrangements can be reached, which discuss preventive and therapeutic tasks in the approach of Western medicine at the appropriate level, both from the organizational and therapeutic aspects. However, studying these - due to epistemological peculiarities -we found that they lack several solution possibilities-which the member organizations of the association can propose based on their 
professional experience and knowledge of the literature. This work was born as a complement to and integration of current studies and measures, primarily of a preventive nature. We will not repeat the current ones, we will only supplement them. The recommendation is about the prevention of the disease, its treatment in the pre-hospital phase, when patients have not yet received medication due to their mild condition.

The COVID-19 pandemic has become a major problem today. The infection capacity of the virus is high, a virus carrier can infect 2-5 people. The disease has a mild course in general, it is extremely dangerous especially for those over 70-80 years of age, suffering from other chronic diseases. Its mortality rate is $3.4 \%$, and in old age it can reach $30 \%$ [18]. However, the news is coming from the American continent that the number of serious patients is increasing even at a younger age. The virus is most likely to mutate. Recent observations suggest that the virus attacks hemoglobin, resulting in impaired oxygen transport capacity and the release of large amounts of oxidized iron into the blood circulation, eliciting an oxidative stress response [17] . This reaction damages the parenchyma of the lungs, which only adds to the difficulties to absorb oxygen. Experience in Lombardy has shown that treatment started in a patient's home reduced the proportion of cases admitted to the intensive care unit. The solution to see a doctor only when one feels the symptoms of pneumonia significantly increases the burdens of intensive care and minimizes the chances of patients survival. Allopathic medicine, even by superhuman efforts and huge technical background can only fight for the lives of patients within limits. If we supplement the applied therapy in the preventional or the early phase, we can reduce the burden of health care. Areas of intervention The central element of allopathic medicine is the diagnosis, the history, therapy, and prevention of the disease, which are determined by the diagnosis. This is why the field of acute care has had such great success, but therapy requires waiting for the diagnosis to be made, i.e., the stage when only acute therapy is effective. Complementary -integrative therapies approach the disease from a different perspective. The primary focus is on the disease process, the system, and connections of the events taking place in the patient's body, psyche, lifestyle, which allow the disease to occur. Until the disease reaches a diagnosis of allopathy, a multi-step process appears so the disease process can be broken down into elements. Using this approach, the prehospital phase of COVID_19 disease was broken down into a series of elements. Each section was analyzed separately in the light of possible actions. In the course of the analysis, we do not go into the separation of prevention and therapy, as these elements are, in our approach, the steps of a (disease process), and therefore inseparable. For this reason, the strategy of the (preventive) fight against the virus is published in the manner of the process approach below.

\section{Virus - spread - contact with the body - reaction with the body - disease symptoms}

\section{Virus}

The virus is a $129.6 \mathrm{~nm}$ diameter RNA virus, essentially a "protein sphere" surrounded by a lipid envelope. The crown is made up of glycoprotein molecules. These bind to the host cell. It uses human angiotensin-converting enzyme 2 (ACEII) as its primary cell receptor, and human C-type lectin (DC / L-SIGN) is also mentioned as an alternative receptor [10]. The virus can escape the interferon-evoked immune response (Nk cells, macrophages, antigen presentation). It replicates primarily in intestinal and respiratory cells. The lipid shell can be broken down by detergents, alcohol, and chlorine. Current antiviral prevention is about breaking down the lipid envelope, the essential tool of which is soapy hand washing.

\section{Spread}

The virus spreads by air, but it also remains infectious on the surface of various objects for a few days. It uses pollens, dust particles, nanoparticles and aerosol surfaces to spread in the air. Due to its size, it does not settle (sedimentation is significant above 2 microns), if it binds to transport material, the process of sedimentation appears [3]. Filter masks usually rule out particles above $600 \mathrm{~nm}$, the difference being in the amount of filtration of the inhaled air. FFP $1(80 \%$ is filtered out due to mismatches, FFP2 is filtered out 94\%, FFP3 99\% is filtered out. So none is suitable for virus screening, but yes for viruses that bind to the transport surface. When using masks, the condensation of the inside of the mask must be taken into account, which, after removing the mask, can provide a suitable adhesive surface for the adhesion of virustransporting substances. This means that using the same mask again after taking it off it is not recommended. The protection interval of a mask is usually 8 hours. Therefore it is highly suggested to wear masks to prevent airway spread.

\section{Air filtration}

The HEPA filters of the air filters used to clean the air in the rooms are suitable for filtering out particles bound 
Citation: I. Szalkai, A. Radnai, F. Karacsony, J. Körmendi-Racz, A Nyerges, G. Hegyi (2020) Possibilities Of Pre-Hospital Intervention In The Prevention And Treatment Of Covid-19 Recommendations Of The Hungarian Integrative Medicine Association. Journal of Medicine and Healthcare. SRC/JMHC/118. DOI: doi.org/10.47363/JMHC/2020(2)110

to the transport material. Ionizers are also able to bind and neutralize microparticles with the help of ozone and negative ions formed by corona discharge. Ozone generators also take advantage of the disinfecting effect of ozone. It is recommended to use such air filters indoors.

\section{Skin protection}

Frequent hand washing prevents skin spread. However, when using hand wash, its detrimental effect on the skin's own defense system must be taken care of. The skin has a proper protective system consisting of the microbiome on the skin, the fat content of the stratum corneum and the elastic adhesion of the cells in the cornea, and the functioning of the immune system in the skin. Due to the deposition of airborne viruses on surface objects, they can be further transported to the mouth with our hands, and they are able to adhere to the intestinal tract. Therefore, hand protection is important.

This may be:

1. careful soapy hand washing (dissolves the lipid envelope of the virus)

2. disinfectant fold hand protection (disinfectant soap, solution, gel) that is effective for a shorter or longer period of time

3. use gloves. Gloves may be warranted if we leave the apartment and go to an area where more people are likely to appear. Dispose of after use.

Hand washing dissolves the lipid sheath of the skin, dries out the stratum corneum, and removes the components of the microbiome. Therefore, once a day, after washing your hands, use a moisturizer. The role of the hand in the infection is to transport the pathogen into the oral cavity. Through the skin, the virus does not invade.

\section{Contact with the organization}

So far, we have been basically dealing with mechanical protection, keeping the virus away from the body. If the virus gets into the gates of infection, we have the following options. In the way that the virus reaches the intestinal and lung cells, it is necessary to eliminate or reduce its amount.

Dry throat and dry cough in addition to high fever are of paramount importance in the initial symptoms of the virus. The loss of smell's sense is a sign of the virus flow through n. olfactory [5]. In the Ayurvedic approach, this means the Vata-pitta symptom group.

\section{What to do?}

1. The mucous membranes (oral cavity, pharynx) should be kept moist. To do this, a sip of lukewarm water and herbal tea must be consumed every quarter of an hour, and the oral cavity must be gargled. Proposed by AYUSH (Ministry of Traditional Medicine of India): Turmeric (Curcuma), cumin, coriander, garlic, black pepper, raisin decoction. Golden milk: 1 tablespoon of turmeric is cooked in $1.5 \mathrm{dl}$ of hot milk. It is recommended to eat this warm in the evening. [15].

2. Nasya - dripping oil into the nostril. It helps to remove mucous deposits, in which the virus-carrying particles can stick, and protects the mucous membrane when coated. The absorption of herbs dissolved in this oil starts from the nasal mucosa. Oil: sesame oil or oily nasal drops. It can be cooked Ashwagandha, Tulsi, ginger, cinnamon, cloves, since they are immunostimulatory and antiviral herbs.

2. When cooking the tea mixtures from these herbs, add 1-1 teaspoon of vegetable powder to 11 of water, cook for 10 minutes and let it cool to drink. It is necessary to consume it during the day.

3. Rinse mouth with silver colloid and / or Grapefruit seed solution.

4. The use of Kaqun water, which is effective against hypoxia and increases NK cell number and function, is recommended to apply.

5. Respiratory protection: The use of expectorants

a. Steam inhalation with essential oils (eucalyptus, thyme, cinnamon, propolis, honey [19])

b. Chest rub with essential oil creams

c. Perform breathing exercises. Prana breathing several times a day, providing complete ventilation of the lungs (deep inhalation with alternating nostrils, slow exhalation 5-10 times), Buteyko breathing (abdominal inhalation through the nose, slow exhalation).

Every organ, tissue, and cell in the body has a protective function. This function is called Ayurveda agni. This function needs to be enhanced, first and foremost, the digestive capacity of the stomach to be able to dissolve the viral protein and lipid envelope.

This requires:

- Eating easily digestible foods

- Use of salty, sour. and spicy foods and spices

- Avoid cold drinks and food

- Digestive spices: ginger, pepper, cinnamon, cloves, cumin, anise, green spices (basil, lavender, oregano, 
peppermint). The point is to spice up more strongly.

- Ayurvedic medicines (supplements): Triphala, Trikatu, Shilajit.

\section{Principles of homeopathic treatment}

Homeopathy is in a crossfire of strong attacks these days. The essence of the treatment is to treat the patient individually, by personally determined, nano dose substances - artificially produced pseudo disease. Several scientific publications have been published on the effectiveness of homeopathy, its mechanism of action is not yet known, we only have hypotheses. There are preparations for general use - we suggest these, but the substantive therapy is individualized, indicated by a homeopathy doctor.

Recommended preparation

Arsenicum Album 30C 1x5 balls for 3 days, monthly repeated.[15] Oscillococcinum 1 dose per month

\section{Reaction with the organism}

The virus that enters the body binds to the cell surface receptors and enters the cell. In this phase three elements can help effectively.

1. Strengthening the body's immune system

2. Use of substances with antiviral activity

3. Elimination of the virus from the body

\section{Strengthening the body's immune system}

Antiviral immunity is linked to NK cells and the activity of macrophages. Both are part of the cellular immune system. [13] Because the virus inhibits the traditional NK cell-activating pathway, NK cell function and / or amount must be enhanced in other ways. Suitable for this are Kaqun water, vitamin C (1-2 gr p.os) and vitamin D (4-10,000 E / day, high dose only for a short time, vitamin $\mathrm{D}$ levels need to be checked), Triphala caps $3 \times 1$, Ashwagandha [2] caps. daily1-2gr, Curcumin [9] caps 1-2 gr / day. Ashwagandha and curcumin, beside immune-stimulating functions, slow down the development of such inflammation markers as cytokines while decreasing their volume in the blood. The Ashwagandha helps to handle the quarantine-neurosis and to treat the immune weakening stress effects. The DIC has recently been emerged to play a role in the effect mechanism of cytokine storms.

A strong stimulator of the immune system is rice extract containing arabinoxylan $[6,14,16]$.
The condition of the microbiome strongly affects the immune status. Replanting the right proportion of the microbiome significantly increases the propensity to heal in all cases. The lung microbiome is quite unique and has less research focus than the intestinal microbiome. It is evident that a normal microbiome also strengthens the capacity of the immune system, while a damaged environment is immunologically associated with a decrease in protection. The microbiome of the body is a complex community of life, and each region affects the other, so we can really protect the microbiome of the lungs if we take care of what's in the gut, don't take antibiotics unnecessarily, and practice proper breathing. The close relationship [8] is known between viral infections and superinfections, the disproportionate increase in risk in the elderly, and the fact that microbial care is an indirect aid, so it is advisable to take a live flora preparation that can form colonies in the small and large intestines. This indirectly helps the immune system to function effectively.

\section{Antiviral agents}

Vitamin C [9], Tulsi (2 g / day), Neem (2 g / day), licorice [4] These plants also stimulate the immune system and have a direct antiviral effect.

\section{Elimination of the virus from the body}

Viral particles can be detected in the feces in some cases, but their infectivity has not been proven. Due to the fact that a significant proportion of people have nutritional intestinal inflammation, the permeability of the intestinal wall is increased, which promotes the circulation of the virus and its deposition in the lungs. When the body encounters a virus, it is therefore important to help it get out of the gut. This is possible with Psyllium (gelling, absorbing polysaccharide) - one teaspoon in 1 glass of water, one liter of fluid should be consumed in one hour, not used with medication, there should be a difference of at least 1-2 hours between taking the drug and Psyllium), Peruvian diatomaceous earth ( one glass in water) and other absorbent materials. We shall keep in mind that these would accelerate rather than slow down intestinal peristaltic motions. Microbiome health protection in this aspect projects prospering results as well.

\section{In case of symptoms}

Symptoms: high fever, dry throat, decreased sense of smell and taste, dry cough. The latter turns into a wet cough and then triggers pulmonary edema, over the course of which pulmonary fibrosis may develop. More recently, a diagnosis 

Medicine and Healthcare. SRC/JMHC/118. DOI: doi.org/10.47363/JMHC/2020(2)110

of oxygen-deficient ARDS has also occurred. The basis of lung lesions is a strong inflammatory process, described as a cytokine storm. The use of curcumin to reduce cytokine levels is recommended. [11] Immunostimulatory and respiratory therapies should be continued during symptomatic periods. Consumption of dissolved oxygen fluid is required to prevent hypoxia [20]. Due to the weakness caused by high fever, the use of herbs that strengthen the body is a must.

\section{In case of fever}

The goal is to keep the fever at a tolerable level, as the fever has an antiviral and immunostimulatory effect, but it weakens the body immensely. It is necessary to consume liquid, light food, hot liquid, salt replacement. For the treatment of fever made of equal proportions of ginger, tulsi, lemongrass, and fennel. In case of a weakened body, it is recommended to take Shilajit ( $1 \mathrm{~g} /$ day).

\section{For dry cough}

Warm sesame oil chest massage, followed by a warm compress. We cook black pepper and turmeric in milk, and the patient drinks this.

Inhalation (steaming) with a solution of silver colloid, eucalyptus, tea tree, cinnamon, chamomile, propolis, mint, anise.

Chest-back wrap with $10 \%$ lavender or thyme oil. A mixture of cloves and honey 3 times a day.

\section{In case of wet cough}

Taking cardamon, cinnamon, Trikatu, Triphala, or making it in tea. Chest heating to facilitate the elimination of secretions using salt pipe.

\section{Use of expectorants}

In the event of worsening symptoms, a hospitalization ensues, which requires supportive, possibly intensive care. The recommendation concerns the pre-hospital phase, during which we try to bring the body to a state before infection and, in case of infection, to keep it in such a way as to prevent the development and worsening of the disease caused by the virus, to help develop immunity; thus indirectly reducing the critical burden on the health care system.

\section{Discussion}

This epidemic has shown that in the case when allopathic medicine does not have effective tools, they do not turn to the descriptions of the complementary sciences due to the blockage of thinking, the system is unable to deviate from the logic of diagnosis of chemical medicine. Both modern natural remedies and ancient ones have many proven and verified options. These methods can be used according to a different logic that still fits into the treatment protocol of hospital treatments. The point is the integrative application and thinking. Their usage varies from culture to culture. TCM is popular in China, Ayurveda, and homeopathy in India, homeopathy in Cuba. In order to improve the longterm results of allopathy, it is necessary to use the tools that consider maintaining the balance of the body primarily, because an organism with a healthy metabolism, immune system, and mental system is more resistant to external damaging factors and has a faster recovery tendency. The seriousness of the disease largely depends on the volume of the viral particles accumulating in the body. For this reason we highly suggest to keep the arrangements preventing invasion along with those that minimize the microbes present by strengthening the immune system itself. It is necessary to overcome the process of flock immunity development without fatalities in excess. The purpose of our study is to help avoid the disease for those in the prodromal symptom period, as well as to help home-care patients as they are on the periphery of general health care services.

\section{References}

1. Borde VU, PP Pangrikar, SU Tekale: Gallic acid in Ayurvedic herbs and formulations. Recent Research in Science and Technology, 2011

2. Bose S, Panda AK, Mukherjee $S$ at all: Curcumin and tumor immune-editing: resurrecting the immune system. Cell Div. 2015 Oct 12;10:6. doi: 10.1186/s13008015-0012-z. eCollection 2015.

3. Csurgai József; Solymosi Máté: Measuring the efficiency of air filters. Military Engineer. 2015 marc. 10:1 62-78.

4. Damle M: Glycyrrhiza glabra (Liquorice) a potent medicinal herb. International Journal of Herbal Medicine 2014; 2(2): 132-136

5. M. Desforges: Human Coronaviruses and Other Respiratory Viruses: Underestimated Opportunistic Pathogens of the Central Nervous System? Viruses 2019, 12, 14; doi:10.3390/v12010014

6. Elsaid A. F., M. Shaheen, M. Ghoneum: Biobran/MGN3 , an arabinoxylan rice bran, enhances NK cell activity in geriatric subjects: A randomized, double-blind, placebocontrolled clinical. Exp Ther Med. 2018 Mar; 15(3): 2313-2320. Published online 2018 Jan 8. doi: 10.3892/ etm.2018.5713

7. Hansen Christine, Ruth E. Taylor-Piliae: What is 
Bowenwork? A Systematic Review. THE JOURNAL OF ALTERNATIVE AND COMPLEMENTARY MEDICINE Volume 17, Number 11, 2011, pp. 10011006. DOI: $10.1089 / \mathrm{acm} .2010 .0023$

8. Hörster R, Rupp J: The new comprehension of pulmonary infections. Pneumologe (Berl). 2020;17(2):105-112. doi: 10.1007/s10405-019-00291-8. Epub 2019 Dec 10.

9. Kim Y, Kim H, Bae S: Vitamin C Is an Essential Factor on the Anti-viral Immune Responses through the Production of Interferon- $\alpha / \beta$ at the Initial Stage of Influenza A Virus (H3N2) Infection. Immune Netw. 2013 Apr;13(2):70-4. doi: 10.4110/in.2013.13.2.70. Epub 2013 Apr 30.

10. Lee N, Qureshi ST:: Other viral pneumonias: coronavirus, respiratory syncytial virus, adenovirus, Hantavirus. Crit Care Clin. 2013 Oct;29(4):1045-68. doi: 10.1016/j. ccc.2013.07.003. Epub 2013 Aug 9.

11. Lim GP, Chu T, Yang F, at al. The curry spice curcumin reduces oxidative damage and amyloid pathology in an Alzheimer transgenic mouse. J Neurosci. 2001;21:83708377

12. Palliyaguru DL, Singh SV, Kensler TW: Withania somnifera: From prevention to treatment of cancer. Mol Nutr Food Res. 2016 Jun;60(6):1342-53. doi: 10.1002/ mnfr.201500756. Epub 2016 Jan

13. Peterson CT, Denniston K, Chopra D: Therapeutic Uses of Triphala in Ayurvedic Medicine J Altern Complement Med. 2017 Aug 1; 23(8): 607-614. doi: 10.1089/ acm.2017.0083

14. Petrovics, G ; Szigeti, Gy ; Hamvas, Sz ; at al: Controlled pilot study for cancer patients suffering from chronic fatigue syndrome due to chemotherapy treated with BioBran (MGN-3-Arabinoxylane) and Targeted Radiofrequency Heat therapy. European Journal of Integrative Medicine 8 : Suppl.2. pp. 29-35. , 7 p. (2016) DOI WoS Scopus

15. Press Information Bureau Government of India. AYUSH: Advisory from Ministry of Ayush for meeting the challenges arising out of spread of Corona Virus in India.07-March-2020 14:35 IST

16. Salama H, E Medhat, M Shaheen, Arabinoxylan rice bran (Biobran) suppresses the viremia level in patients with chronic HCV infection: A randomized trial. Int J Immunopathol Pharmacol. 2016 Dec;29(4):647-653.
Epub 2016 Oct 31.

17. Whenzhong Liu,Hualan Li: https://chemrxiv.org/ articles/COVID-19_Disease_ORF8_and_Surface_ Glycoprotein_Inhibit_Heme_Metabolism_by_Binding to_Porphyrin/11938173

18. Zhou F, Yu T, Du R, at al. Clinical course and risk factors for mortality of adult inpatients with COVID-19 in Wuhan, China: a retrospective cohort study. Lancet. 2020 Mar 28;395(10229):1054-1062. doi: 10.1016/S01406736(20)30566-3. Epub 2020 Mar 11.

19. Wei Yang, Fu-liang Hu, Xiao-feng Xu (2020) Bee venom and SARS-CoV-2,Toxicon, Vol. 181, pp69-70.doi: 10.1016/j.toxicon.2020.04.105

20. I Szalkai: High oxygen-containing water and their therapeutic effect. J. Comlementer Med. Alt Healthcare 3(4):
Copyright: (2020 Szalkai Iván. This is an open-access article distributed under the terms of the Creative Commons Attribution License, which permits unrestricted use, distribution, and reproduction in any medium, provided the original author and source are credited. 